\title{
Reciprocal Regulation of the Epstein-Barr Virus BamHI-F Promoter by EBNA-1 and an E2F Transcription Factor
}

\author{
NANCY S. SUNG,${ }^{1,2} \dagger$ JULIE WILSON,${ }^{1}$ MATTHEW DAVENPORT, ${ }^{1,2}$ NIRUPAMA D. SISTA, ${ }^{1}$ \\ AND JOSEPH S. PAGANO ${ }^{1,2,3 *}$ \\ UNC Lineberger Comprehensive Cancer Center, ${ }^{1}$ Department of Microbiology and Immunology, ${ }^{2}$ and Department of \\ Medicine, School of Medicine, ${ }^{3}$ University of North Carolina at Chapel Hill, Chapel Hill, North Carolina 27599
}

Received 22 February 1994/Returned for modification 2 May 1994/Accepted 1 August 1994

\begin{abstract}
The Epstein-Barr virus BamHI-F promoter (Fp) is one of three used to transcribe the EBNA latency proteins, in particular, EBNA-1, the only viral gene product needed for episomal replication. Fp is distinguished by possession of the only EBNA-1 binding sites (the $Q$ locus) in the Epstein-Barr virus genome outside oriP. Activity of $F p$ is negatively autoregulated by interaction of EBNA-1 at two sites in the $Q$ locus, which is situated downstream of the RNA start site. We demonstrate in transient assays that this EBNA-1-mediated repression of Fp can be overcome by an E2F transcription factor which interacts with the DNA at a site centered between the two EBNA-1 binding sites within the Q locus. An E2F-1 fusion protein protects the sequence $5^{\prime}$-GGATGGCGGGTAATA-3' from DNase I digestion, and a DNA probe containing this sequence binds an E2F-specific protein complex from cell extracts, although this region is only loosely homologous with known consensus binding sites for E2F transcription factors. In mobility shift assays, E2F can displace the binding of EBNA-1 from the $Q$ locus but not from oriP, where the E2F binding site is not present. E2F also activates expression of $F p$ in epithelial cells. These findings identify a potentially new binding site for members of the E2F family of transcription factors and suggest that such a factor is important for expression of EBNA-1 in lymphoid and epithelial cells by displacing EBNA-1 from the Q locus. In addition, the possibility that $\mathrm{Fp}$ activity is under cell cycle control is raised. Since the supply of functional E2F varies during the cell cycle and since in these assays overexpression of E2F can overcome repression of Fp by EBNA-1, control of transcription of EBNA-1 mRNA by cell cycle regulatory factors may help to bring about ordered replication of episomes.
\end{abstract}

Epstein-Barr virus (EBV) is associated with the development of malignancies (lymphomas and carcinomas of the nasopharynx) in both of the cell types it infects $(10,45,59)$. In each of these tumors, the viral genome exists as a circular episome, characteristic of EBV latency (42). The key gene required for initiation and maintenance of latent infection encodes Epstein-Barr nuclear antigen 1 (EBNA-1). By binding to specific repeated DNA sequence motifs at the origin of plasmid replication (oriP) (38), EBNA-1 activates both episomal replication and the oriP transcriptional enhancer $(46,47$, $60,65)$ and thus acts as a positive regulatory protein.

In type 1 Burkitt's lymphoma cells, as well as in nasopharyngeal carcinoma, the EBNA-1 transcript arises from Fp, a promoter in the Bam HI-F fragment of the EBV genome (31, $49,50,52,58)$. The major RNA start site for Fp lies $200 \mathrm{bp}$ upstream of two imperfect yet functional binding sites for the EBNA-1 protein (the Q locus), the only other location for EBNA-1 binding sites in the EBV genome $(1,29,46)$. Expression of $\mathrm{Fp}$ is negatively autoregulated by EBNA-1 acting through the $Q$ locus $(51,62)$. This EBNA-1-mediated repression can be transferred to a heterologous promoter and only requires one EBNA-1 binding site (62). The strong autorepression of Fp by EBNA-1 raises the question of how Fp can be activated in EBV-infected cells, all of which express EBNA-1.

\footnotetext{
* Corresponding author. Mailing address: Lineberger Comprehensive Cancer Center, The University of North Carolina at Chapel Hill, 102 UNC Lineberger Comprehensive Cancer Center, Chapel Hill, NC 27599. Phone: (919) 966-3036. Fax: (919) 966-3015. Electronic mail address: JP000732@UNC.edu.

$\dagger$ Present address: Institute for Virology, Chinese Academy of Preventive Medicine, Beijing, People's Republic of China.
}

In this paper, we show that while Fp is repressed by EBNA-1, it can also be activated by an E2F-like transcription factor which binds to DNA within the Q locus and that the activity of the promoter is reciprocally regulated by these cellular and viral proteins.

\section{MATERIALS AND METHODS}

Cell lines. Raji (44) is a latently infected EBV-positive Burkitt's lymphoma B-cell line, and Jurkat is an EBV-negative human T-cell line. SVK is a human keratinocyte cell line (35). All cells were maintained at $37^{\circ} \mathrm{C}$ in a $5 \% \mathrm{CO}_{2}$ environment. Lymphoid cells were grown in RPMI medium supplemented with $10 \%$ fetal calf serum.

Recombinant phagemid constructs. A series of phagemid constructs, $\mathrm{pF} 1, \mathrm{pF} 2, \mathrm{pF} 3, \mathrm{pF} 4, \mathrm{pF} 2 \mathrm{x}, \mathrm{pF} 12, \mathrm{pF} 13 \mathrm{~d}$, and $\mathrm{pF} 13$, containing various amounts of sequence flanking the Fp RNA start site, were generated by PCR amplification of genomic DNA from the B95-8 cell line, using primers specific for the Fp region. $5^{\prime}$ and $3^{\prime}$ primers contained HindIII and $X b a I$ adapters, respectively. The resulting PCR products were then inserted $5^{\prime}$ of the chloramphenicol acetyltransferase (CAT) gene in the phagemid vector pBSCAT (16) (Fig. 1A). The sequences included in constructs $\mathrm{pF} 1, \mathrm{pF} 2, \mathrm{pF} 3, \mathrm{pF} 4$, and $\mathrm{pF} 2 \mathrm{x}$, relative to the RNA start site $(50,52)$, are shown in Fig. 1A, and those for constructs pF12, pF13d, and pF13 are shown in Fig. 2.

Construct pQEco was generated by two-step PCR of a pF13 DNA template. Degenerate oligonucleotide primers were used to mutate $3 \mathrm{bp}$ within the region of the $\mathrm{Q}$ locus protected from DNase I digestion by the glutathione $S$-transferase (GST)RBP-3 fusion protein. The footprinted sequence was changed 

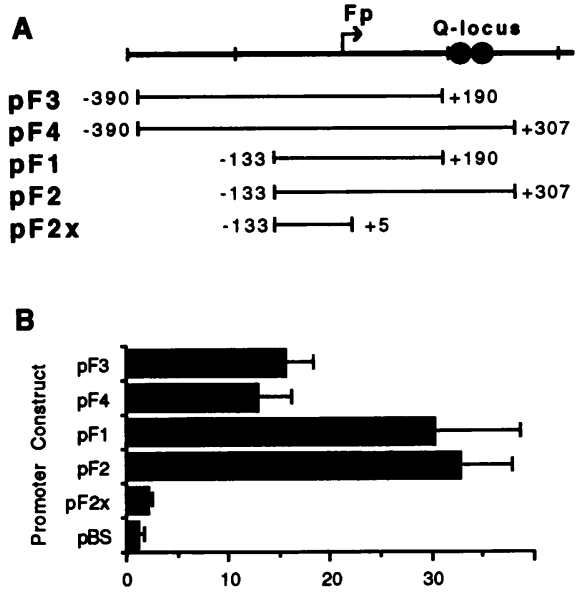

C

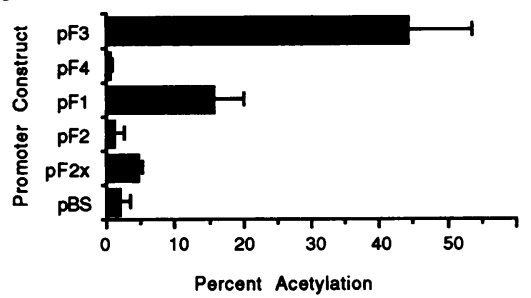

FIG. 1. Schematic representation of $F$ promoter constructs used in transient-transfection assays. (A) RNA start site for Fp, as determined by Sample et al. (50) and Schaefer et al. (52), represented as a bent arrow. Q-locus (filled circles), the two low-affinity binding sites for the EBNA-1 protein. Promoter constructs are shown below, with coordinates relative to the RNA start site. Each was linked to the CAT gene in phagemid vector pBSCAT (16). (B) Constitutive activity of Fp constructs in EBV-negative Jurkat cells. Promoter activity is shown as average percent acetylation. (C) Constitutive activity of Fp constructs in EBV-positive Raji cells.

to 5'-CTACCGAATTCCGGGTAATA-3'; mutated bases are underlined.

The constructs pRSV E1a Neo and pRSV E1 $a_{928}$ Neo were generous gifts from David Johnson of Joseph Nevins' laboratory. The former consists of a pRC Rous sarcoma virus vector (Invitrogen) which expresses wild-type E1A protein, and the latter has the same vector backbone but expresses mutant E1A which cannot bind to $\mathrm{Rb}$ and therefore cannot release $\mathrm{E} 2 \mathrm{~F}$ (27a).

The CMV-RBP-3 construct, kindly provided by $\mathrm{K}$. Helin, contains the cDNA encoding amino acids 88 through 437 of the E2F-1 transcription factor under the control of the cytomegalovirus (CMV) immediate-early (IE) promoter (22). The pHD101-3 vector, containing the CMV-IE promoter in a pGem-2 plasmid, was used as a negative control (13).

DNA transfections. Plasmid DNA was amplified in Escherichia coli and purified through Qiagen columns. For each sample, $10 \mu \mathrm{g}$ of plasmid DNA was electroporated (40) into $1 \times 10^{7}$ lymphoid or $0.5 \times 10^{7}$ epithelial cells at $1,500 \mathrm{~V}$, using the University of Wisconsin Zapper electroporation unit. Cells were then suspended in $5 \mathrm{ml}$ of RPMI 1640 medium supplemented with $10 \%$ fetal calf serum and incubated for $48 \mathrm{~h}$ at $37^{\circ} \mathrm{C}$ in $5 \% \mathrm{CO}_{2}$.

CAT assays. Extracts were prepared by washing cell pellets twice in phosphate-buffered saline solution (PBS), resuspension in $200 \mu \mathrm{l}$ of $0.25 \mathrm{M}$ Tris- $\mathrm{HCl}(\mathrm{pH} \mathrm{7.5)}$, and four cycles of freeze-thaw. Reactions were carried out, as described previ-
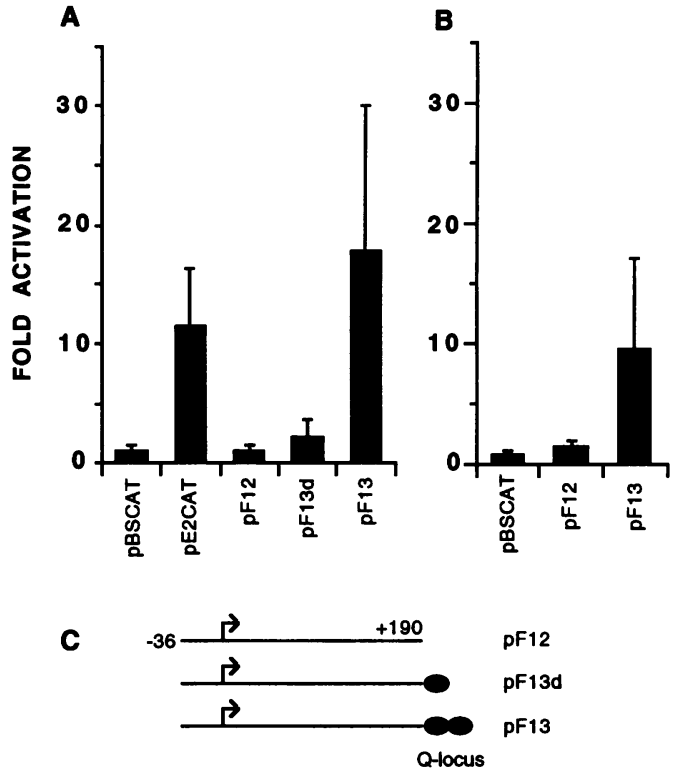

FIG. 2. E2F-1 activates Fp in transient promoter assays. Five micrograms of each promoter construct was cotransfected with $5 \mu \mathrm{g}$ of either CMV-RBP-3 or pHD101-3, a negative control vector, into the EBV-positive cell line Raji (A) and into the EBV-negative human keratinocyte line SVK (B). Schematic representations of constructs $\mathrm{pF} 12, \mathrm{pF} 13 \mathrm{~d}$, and $\mathrm{pF} 13$ are shown below. $\mathrm{pE} 2 \mathrm{CAT}$, a positive control for $\mathrm{E} 2 \mathrm{~F}$ responsiveness, contains the adenovirus $\mathrm{E} 2$ promoter linked to the CAT gene. Results are expressed as the relative promoter activity in the presence and absence of CMV-E2F-1.

ously (18), by incubating each sample with acetyl coenzyme A and $\left[{ }^{14} \mathrm{C}\right]$ chloramphenicol at $37^{\circ} \mathrm{C}$ for $2 \mathrm{~h}$. Acetylated reaction products were separated by thin-layer chromatography, visualized by autoradiography, and quantitated by scintillation counting or by scanning on a Molecular Dynamics PhosphorImager. Percent acetylation is calculated as the ratio of counts per minute in the acetylated reaction products to counts per minute in the entire sample, and fold activation is calculated as the percent acetylation relative to a negative or positive control value.

Preparation of ${ }^{32} \mathbf{P}$-labelled probes for mobility shift assays. DNA probes were generated by annealing oligonucleotides spanning the regions of interest and filling in any singlestranded overhang with the Klenow enzyme. Probes were end labelled with polynucleotide kinase and are diagrammed in Fig. 3A, 5A, and 7A.

Preparation of whole-cell extracts. Approximately $10^{8}$ cells were washed with PBS and resuspended in extraction buffer containing $20 \mathrm{mM} \mathrm{N}$-2-hydroxyethylpiperazine- $N^{\prime}$-2-ethanesulfonic acid (HEPES), $450 \mathrm{mM} \mathrm{NaCl}, 0.2 \mathrm{mM}$ EDTA, $25 \%$ glycerol, $0.5 \mu \mathrm{g}$ of leupeptin per $\mathrm{ml}, 1 \mu \mathrm{g}$ of aprotinin per $\mathrm{ml}$, $0.5 \mu \mathrm{g}$ of pepstatin per $\mathrm{ml}$, and $0.5 \mu \mathrm{M}$ dithiothreitol (DTT). Extracts were then sonicated on ice for 10 short bursts, and debris was removed by centrifugation at $12,000 \times g$ for $20 \mathrm{~min}$ at $4^{\circ} \mathrm{C}$. Aliquots of the supernatant fluids were stored at $-70^{\circ} \mathrm{C}$. Protein determinations were done with the Bradford protein assay.

Preparation of GST fusion proteins. The GST-RBP-3 construct, containing amino acids 88 through 437 of the E2F-1 transcription factor, was provided by $\mathrm{K}$. Helin (22). The full-length, wild-type GST-E2F-1 construct and the GSTE2F-1 DNA-binding mutant, pGEX2T-E2F-1 Eco138, were kindly provided by D. Cress of Joseph Nevins' laboratory (11). 
The GST-EBNA-1 construct was made by inserting an RsaIMscI DNA fragment, which contains the EBNA-1 open reading frame minus the first seven amino acids and the Gly-Ala repeats, into the SmaI site of pGEX 1N (57). Overnight cultures of $E$. coli transformed with this plasmid were induced with $0.1 \mathrm{mM}$ isopropyl- $\beta$-D-thiogalactopyranoside (IPTG) for 3 $\mathrm{h}$. Induced cultures were pelleted, lysed in a $1 \%$ Triton X-100 solution, and sonicated. GST-EBNA-1 fusion protein was purified by incubating the lysate with glutathione-agarose beads. Following three washings with PBS, purified fusion protein was eluted with $5 \mathrm{mM}$ reduced glutathione in $50 \mathrm{mM}$ Tris- $\mathrm{HCl}$ (pH 8.0).

Gel mobility shift assays. Binding reactions with whole-cell extracts contained $25 \mathrm{mM}$ Tris (pH 7.5), $125 \mathrm{mM} \mathrm{NaCl}, 1.25$ mM DTT, $12.5 \%$ glycerol, $0.05 \mathrm{mg}$ of sonicated salmon sperm DNA per ml, $0.06 \%$ Nonidet (NP-40), $6.25 \mathrm{mM} \mathrm{MgCl}_{2}$, and $0.06 \mathrm{mg}$ of bovine serum albumin (BSA) per ml. After preincubation for $5 \mathrm{~min}$ at $22^{\circ} \mathrm{C}, 25,000 \mathrm{cpm}$ of radiolabelled probe was added, and the mixture was incubated for $20 \mathrm{~min}$ at $22^{\circ} \mathrm{C}$. Samples were then electrophoresed at $4^{\circ} \mathrm{C}$ through nondenaturing polyacrylamide gels in $1 \times$ Tris-borate-EDTA buffer. Protein-DNA complexes were visualized by autoradiography.

For the supershift reactions, binding reaction mixtures containing whole-cell Jurkat extracts were incubated on ice with $0.5 \mu \mathrm{l}$ of either monoclonal antibody to E2F (KH95; contributed by Nick Dyson and Ed Harlow) (23) or EBNA-1 (EBNA.OTx1; contributed by J. Middeldorp) (7) for $1 \mathrm{~h}$ before the addition of radiolabelled probe.

Binding mixtures for the displacement mobility shift assays were solutions of $20 \mathrm{mM}$ Tris- $\mathrm{HCl}(\mathrm{pH} \mathrm{7.5),} 100 \mathrm{mM} \mathrm{NaCl}, 1$ mM DTT, $0.05 \mathrm{mg}$ of sonicated salmon sperm DNA per ml, $10 \%$ glycerol, $0.5 \% \mathrm{NP}-40$, and $5 \mathrm{mM} \mathrm{MgCl}_{2}$. One microgram of purified GST-EBNA-1 was incubated with $5,000 \mathrm{cpm}$ of labelled Qd for 15 min to allow binding. Subsequently, purified GST-E2F-1, GST-E2F-1 DNA-binding mutant, GST-Z, or GST was added and incubated for an additional $20 \mathrm{~min}$.

Gel shift competitors. All competitors for the gel mobility shift assays were annealed oligonucleotides that were purified by phenol-chloroform extractions and passed through a G-25 column (Boehringer-Mannheim), except for the thymidine kinase (TK) competitor (a gift from David Johnson in Joseph Nevins' laboratory). The sequences for the oligonucleotides are as follows: human dihydrofolate reductase promoter (DHFR), 5'-CCACAATTTCGCGCCAAACTTGAC-3', adenovirus type 5 E2 promoter (E2), 5'-CGTAGTTTTCGCGCTTAAA TTTGAGAAAGGGCGCGAAACTAGTC-3'; human c-myc promoter (c-myc), 5'-CAGAGGCTTGGCGGGAAAAAGA ACGGAGGGAGGGATCGCGCTGAGTA-3', human TK promoter, 5'-TCGACGGGGCGGGCTGCGGCAAATCTC CCGCCAGTCAGCGGCCGGGCGCTGATTGGCCC-3'; one binding site from the adenovirus E2 promoter (E2F), 5'-AATTTGAGAAAGGGCGCGAAACTAGTC-3'; and the mutant control for E2F (E2Fm), 5'-AATTTGAGAAACTA GAGTCTGCTAGTC-3' (reviewed in reference 41).

DNase I footprinting. A DNA probe, radiolabelled on the noncoding strand, was prepared by digesting the pQa plasmid construct, which contains Fp sequences from +134 to +307 cloned into the $X b a I$ site of the pBSCAT vector, with HindIII and PvuII. The resulting fragment, which contained Fp sequences from +134 to +260 , was gel purified and filled in with radiolabelled nucleotides, using the Klenow enzyme. Binding reaction mixtures contained $7 \mathrm{mM} \mathrm{MgCl}_{2}, 1 \mu \mathrm{g}$ of sonicated calf thymus DNA per ml, $0.14 \mu \mathrm{g}$ of BSA, $0.75 \% \mathrm{NP}-40,4 \mathrm{mM}$ HEPES (pH 7.6), $8 \mathrm{mM} \mathrm{KCl,} 0.02 \mathrm{mM}$ ethylene glycol-bis( $\beta$ aminoethyl ether)- $N, N, N^{\prime}, N^{\prime}$-tetracetic acid (EGTA), $0.5 \mathrm{mM}$ EDTA, 0.4 mM DTT, and $8.3 \%$ glycerol. Following incubation at $22^{\circ} \mathrm{C}$ for $20 \mathrm{~min}, 0.15 \mathrm{U}$ of DNase I (Promega) was added for $1 \mathrm{~min}$. Digestion was stopped by the addition of a solution containing $100 \mathrm{mM} \mathrm{NaCl}, 100 \mathrm{mM}$ Tris-Cl (pH 8.0), $20 \mathrm{mM}$ $\operatorname{EDTA}(\mathrm{pH} 8.0$ ), $0.1 \%$ SDS, $100 \mu \mathrm{g}$ of proteinase $\mathrm{K}$ per $\mathrm{ml}$, and $100 \mu \mathrm{g}$ of glycogen per ml. Reaction products were extracted with phenol-chloroform, ethanol precipitated, electrophoresed on a $6 \%$ polyacrylamide-urea denaturing gel, and visualized by autoradiography.

\section{RESULTS}

Constitutive activity of $\mathrm{Fp}$ in infected and uninfected lymphoid cells. To study promoter activity, a set of phagemid constructs containing various amounts of DNA sequence flanking the Fp RNA start site was made. Promoter inserts were generated by PCR amplification of genomic DNA from the B95-8 strain of EBV and linked to the CAT gene in the phagemid vector pBSCAT (16). Constructs shown in Fig. 1A were transfected by electroporation into different cell lines, and promoter activity was gauged by CAT assay.

When constructs $\mathrm{pF} 1$ through $\mathrm{pF} 4$ were transfected into the EBV-negative Jurkat cell line, Fp was constitutively active (Fig. 1B). When the constructs were transfected into the EBV-positive Raji cell line, however, promoter activity was completely abolished in those constructs which contained the downstream Q locus, to which EBNA-1 binds with a low affinity (Fig. 1C). This result confirms that a factor present in EBV-infected cells, presumably EBNA-1, acts to repress Fp activity through interaction with the consensus binding sites downstream of the Fp transcriptional start site (51).

Promoter construct $\mathrm{pF} 2 \mathrm{x}$, which contained just 5 bp of downstream sequence, was far less active than constructs $\mathrm{pF} 1$ and $\mathrm{pF} 3$, which contained $190 \mathrm{bp}$ of downstream sequence (Fig. 1B and C), in both infected and uninfected cells, suggesting the existence of a downstream positive regulatory element located between +5 and +190 .

E2F-1 activates Fp in transient promoter assays. To determine whether a known cellular factor might serve to activate $F p$, the DNA sequence of the downstream region was scanned for known transcription factor binding sites. No perfect match was found; however, a sequence resembling the consensus binding site for the E2F-1 transcription factor was identified within the downstream positive regulatory region, between nucleotides +172 and +181 relative to the RNA start site (TTTGCGAAAA). As shown in Fig. 2A, the pF13 construct normally under EBNA-1 repression in EBV-infected Raji cells was activated an average of 26-fold when cotransfected into Raji cells with the CMV-RBP-3 plasmid, which expresses the E2F-1 protein under the control of the CMV IE promoter. In addition, in the human keratinocyte cell line SVK, pF13 showed an average of 8.6-fold activation. Interestingly, CMVRBP-3 did not transactivate the shorter constructs, $\mathrm{pF} 12$ or $\mathrm{pF} 13 \mathrm{~d}$, both of which contained the suspected positive regulatory region. Unexpectedly, therefore, the E2F-responsive region of Fp appears to lie within the $\mathrm{Q}$ locus $(+190$ to +307$)$ rather than in the region from +5 to +190 . Moreover, the E2F-responsive region is functional in epithelial as well as lymphoid cells.

A fusion protein expressing the E2F-1 transcription factor binds specifically to the $F$ promoter. To determine whether the E2F-1 protein interacted directly with DNA sequence in the $F$ promoter region (Fig. 3A), mobility shift assays were performed with purified GST-RBP-3 fusion protein, kindly provided by $K$. Helin (22). This fusion protein formed three complexes with the Qa probe, which extends from +134 to +307 , and encompasses both the positive regulatory element 

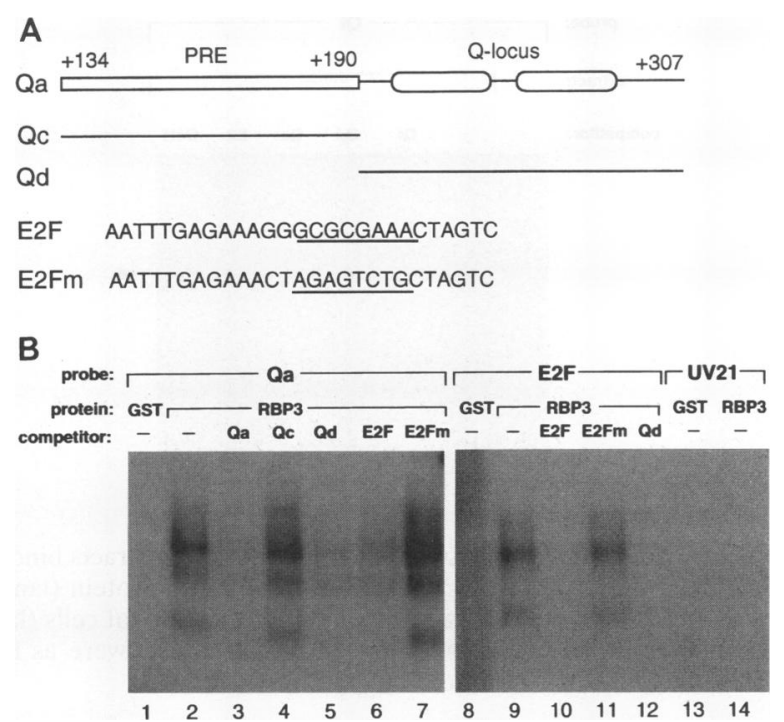

FIG. 3. Interaction of an E2F-1 fusion protein with the Fp downstream regulatory region. (A) DNA sequence of probes and competitors used in mobility shift assays. (B) Labelled DNA probes shown were incubated with either GST protein (lanes 1,8 , and 13) or with GST-RBP-3 protein (lanes 2-7, 9-12, and 14). UV-21 is a DNA probe derived from the mouse major histocompatibility complex class II regulatory region and contains an NF- $\mathrm{kB}$ site (53).

identified earlier and the $Q$ locus (Fig. 3B, lane 2). Formation of these complexes was specifically inhibited with a 100 -fold excess of unlabelled E2F-binding probe (Fig. 3B, lane 6) but not by a 100-fold excess of E2Fm (Fig. 3B, lane 7), which contains a mutated E2F-binding site that abolishes binding of E2F. These complexes were also specifically inhibited with a 100-fold excess of unlabelled Qa and Qd probes (Fig. 3B, lanes 3 and 5; probes diagrammed in Fig. 3A) but not by the Qc probe (lane 4).

As expected, the GST-E2F-1 fusion protein formed complexes with a labelled probe (E2F) containing a consensus E2F-1-binding site (Fig. 3B, lane 9); a 100-fold excess of unlabelled E2F and Qd probes competed with complex formation (Fig. 3B, lanes 10 and 12), but E2Fm did not (Fig. 3B, lane 11). The GST-E2F-1 fusion protein did not interact with a nonspecific DNA probe, UV21, containing an NF- $\mathrm{KB}$ binding site (Fig. 3B, lanes 13 and 14) (53).

Although the Qd probe does not contain a perfect consensus E2F-1 binding site, these results indicate that it is able to interact directly and specifically with the E2F-1 fusion protein generated by GST-RBP-3. In addition, E2F-Qa complex formation is not inhibited with the Qc oligonucleotides, a result that correlates with the functional data in Fig. 2 and suggests that the E2F-responsive region of $\mathrm{Fp}$ is within the $\mathrm{Q}$ locus.

An E2F-1 fusion protein interacts at a site centered between the EBNA-1 binding sites in the $Q$ locus. The interaction of E2F-1 with the Qa probe was localized by DNase I footprinting. As shown in Fig. 4, binding of GST-RBP-3 to the Qa probe specifically protected a region extending from +214 to +235 relative to the RNA start site of Fp $(50,52)$. Interestingly, this region is only loosely homologous to known consensus binding sites for E2F-1. Furthermore, the E2F-1 footprint overlaps with parts of the two low-affinity binding sites for the EBNA-1 protein that define the $Q$ locus. An area of incomplete protection extending from +191 to +204 was also

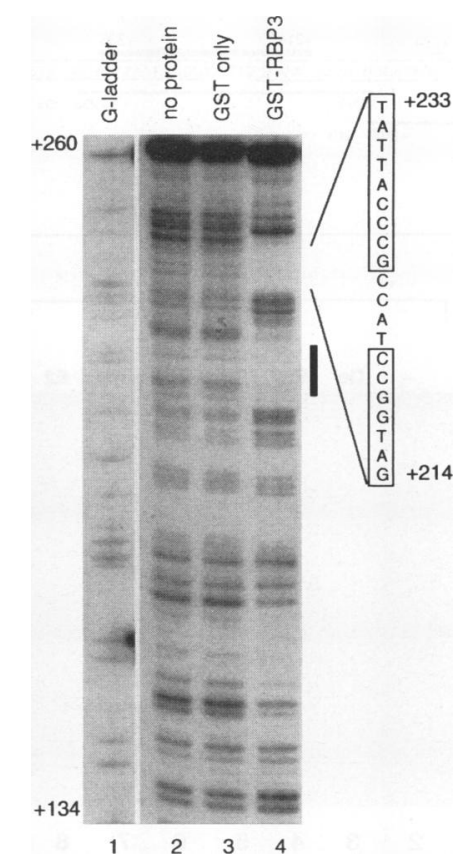

FIG. 4. DNase I footprinting of E2F binding in the Fp downstream regulatory region. An end-labelled probe extending from +134 to +260 , relative to the Fp RNA start site, was digested with DNase I following incubation with no protein (lane 2), GST protein (lane 3), or GST-RBP-3 (lane 4). Lane 1 contains a G ladder of the same probe. Protected sequence is shown at right. Nucleotides included in the EBNA-1 binding sites are boxed. Heavy line indicates an additional minor footprint.

detected. As expected from the functional data, the E2F fusion protein did not protect sequence in the downstream positive regulatory element between nucleotides +134 and +190 .

The $Q$ locus binds an E2F-like protein complex in whole-cell extracts. Two specific protein complexes were generated when the Qd probe was incubated with whole-cell extracts from Jurkat cells (data not shown). Two probes that spanned the footprinted portions of the Qd probe, Qe $(+209$ to +235$)$ and Qf $(+186$ to +209$)$ (Fig. 5A), were incubated with Jurkat cell extracts in mobility shift assays (Fig. 5B). The Qe probe formed one specific band (Fig. 5B, lane 2) that could be inhibited well with a 200 -fold excess of self (Fig. 5B, lane 3 ), and cold competitors from the E2F sites in the human c-myc promoter and the adenovirus E2 promoter (Fig. 5B, lanes 7 and 8 , respectively). It could be competed to some extent by the E2F sites from the human TK promoter (Fig. 5B, lane 5), but not by the E2F sites from the DHFR promoter (Fig. 5B, lane 6). Interestingly, when only one E2F site from the adenovirus E2 promoter was used (Fig. 5B, lane 4), it competed poorly. Oct-1 and SP-1 oligonucleotides were used as negative controls (Fig. 5B, lanes 9 and 10, respectively). As an additional control, a labelled probe containing one E2F site from the adenovirus E2 promoter was inhibited by all of the E2F sites described above as well as partially by Qe (data not shown). Titrations with E2, TK, and E2F oligonucleotides suggested that a 100 -fold excess of $\mathrm{E} 2$ was sufficient to compete with Qe (data not shown).

In order to confirm the presence of E2F in the complex with Qe, a specific monoclonal antibody to E2F, KH95 (23), was used. The antibody supershifted the Qe complex as well as the complex on the E2F probe (Fig. 5C, lanes 1 and 3, respective- 


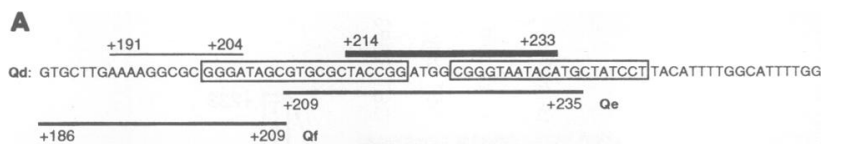

B
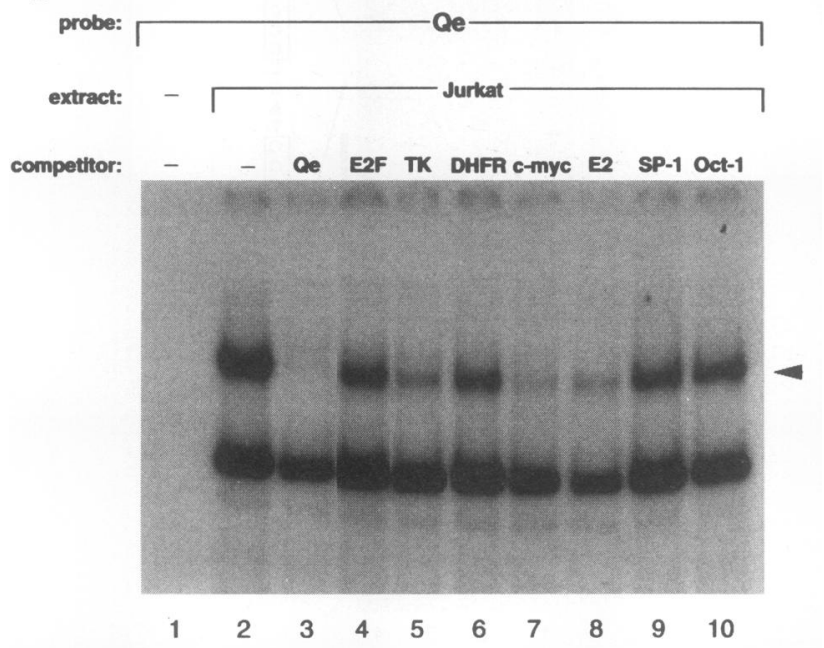

C

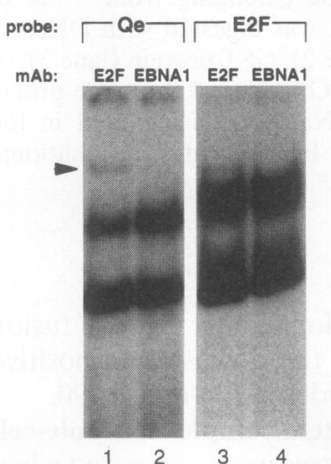

FIG. 5. An E2F-1-like complex in whole-cell extracts binds to the footprinted region of Fp. (A) Footprinted portion of the larger Qd probe is indicated by the bars above the sequence. Bars on the bottom indicate the region used for probes in mobility shift assays with whole-cell extracts. (B) The minimal Qe probe was incubated with either no protein (lane 1) or $10 \mu \mathrm{g}$ of Jurkat whole-cell extracts (lanes 2 to 10 ) and inhibited with 200 -fold excess E2F sites from various promoters. E2F complex is indicated by the arrow. (C) Labelled Qe probe (left panel) or E2F probe (right panel) was incubated with $10 \mu \mathrm{g}$ of whole-cell extracts from Jurkat cells and $0.5 \mu \mathrm{l}$ of a monoclonal antibody to either E2F (lanes 1 and 3) or EBNA-1 (lanes 2 and 4). Arrowhead indicates the supershifted band.

ly). The complexes on the Qe or the E2F probe were not supershifted by EBNA-1 monoclonal antibody EBNA.OTx1 (7).

The footprinting studies revealed another region of interaction with E2F (+191 to +204). A probe, Qf (Fig. 5A), containing this site also formed a specific band when incubated with Jurkat extracts (Fig. 6, lane 2). This complex bound with reduced affinity, as suggested by footprinting data, and was inhibited with Qe and E2F sites from the E2 promoter (Fig. 6, lanes 5 and 6, respectively). Therefore, our results indicate that there are two distinct sites in Fp which bind E2F. The DNA sequences of these regions had hitherto not been described as conventional E2F-binding sites.

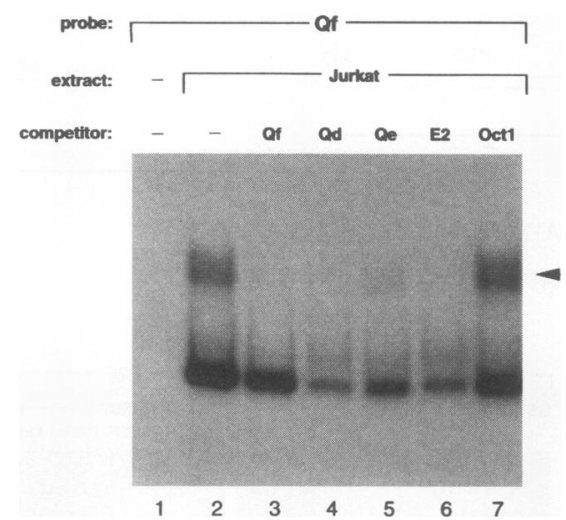

FIG. 6. An E2F transcription factor in whole-cell extracts binds to Qf. Qf probe (Fig. 5A) was incubated with either no protein (lane 1) or with $20 \mu \mathrm{g}$ of whole-cell extract from uninfected Jurkat cells (lanes 2 to 7). Oligonucleotide competitors (200-fold excess) were as indicated. E2F complex is indicated by the arrowhead.

An E2F-1 fusion protein displaces EBNA-1 binding from the $Q$ locus but not from oriP. As demonstrated, E2F-1 activates $\mathrm{Fp}$ in transient promoter assays. Furthermore, the major E2F-1 DNase I footprint lies between, and partially overlaps, the two EBNA-1 sites within the $Q$ locus. Therefore, the ability of E2F to displace EBNA-1 binding from the $Q$ locus was investigated by mobility shift assays. A purified GST-EBNA-1 fusion protein formed a specific complex with the $\mathrm{Qd}$ probe (Fig. 7B, lane 5). A purified, full-length GST-E2F-1 fusion protein also formed a specific complex with a mobility different from that of the GST-EBNA-1 complex (Fig. 7B, lane 4). The addition of increasing concentrations of the GST-E2F-1 fusion protein to prebound GST-EBNA-1 caused a displacement of GST-EBNA-1 from the Qd probe and the formation of the E2F complex (Fig. 7, lanes 6 to 10). As expected, a GST-E2F-1 mutant that is unable to bind DNA (lane 3) did not displace the EBNA-1 complex (lane 11). GST and a GST-Z fusion protein, used as negative controls, were also unable to displace prebound GST-EBNA-1 (lanes 12 and 13, respectively). These results suggest that an E2F transcription factor displaces EBNA-1 by binding to sequences centered between the two EBNA-1 binding sites in the $Q$ locus.

As shown in Fig. 7A, within the E2F-footprinted region is a 15-bp sequence that is unique to the Q-locus probe (boldface line above sequence); partly protected sequence is indicated by the thin line. This 15-bp element is found nowhere among any of the 24 EBNA-1 binding sites within oriP. This was confirmed by the inability of GST-E2F-1 to bind to oriP (Fig. 7B, lane 18). The ability of E2F-1 to displace EBNA-1 from oriP was examined as a further control. GST-EBNA-1 formed a specific complex with the oriP probe (Fig. 7B, lane 17) and was not displaced by the addition of GST-E2F-1 (Fig. 7B, lane 15). This result indicates that $E 2 F$ recognizes sequences specific to the $\mathrm{Q}$ locus. Furthermore, the displacement of EBNA-1 from the $\mathrm{Qd}$ probe by E2F is specific to sequences contained in the $\mathrm{Q}$ locus.

Point mutations within the E2F-1 binding element abolish E2F responsiveness. To confirm that $E 2 F$ responsiveness could be mediated by DNA sequence within the $Q$ locus, three point mutations were introduced into the DNase I-footprinted region (5'-CTACCGAATTCCGGGTAATA-3'; mutated bases are underlined). This mutated construct, pQEco, which did not form an E2F complex with Jurkat cell extracts (data not shown), displayed constitutive activity comparable to that of 

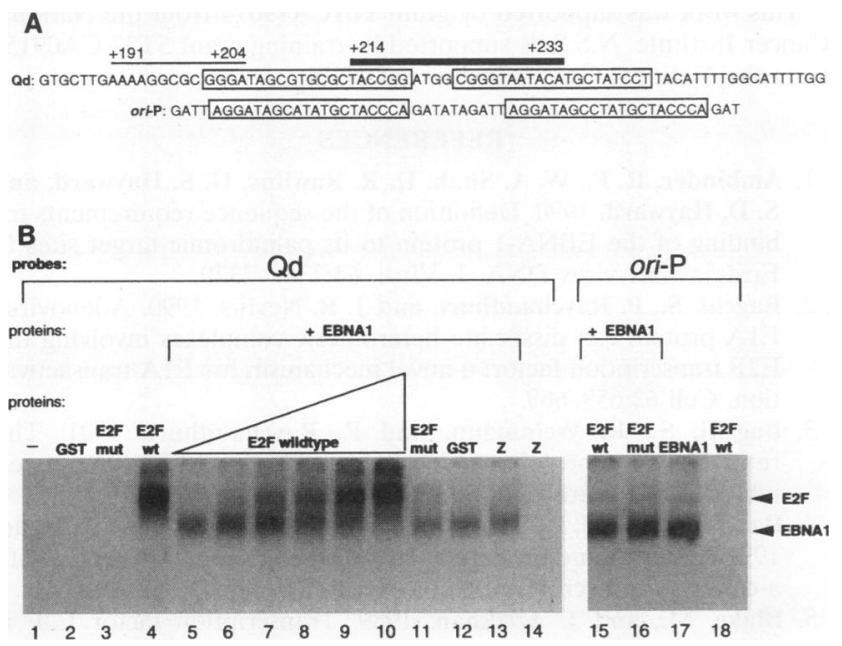

FIG. 7. E2F displaces EBNA1 binding from the $Q$ locus but not from oriP. (A) Sequences of probes used for mobility shift assays. Bars indicate the two E2F footprinted regions $(+191$ to +204 and +214 to +235 ) of the Qd probe. Boxed regions indicate EBNA-1 binding sites. (B) Qd was used as a probe in the left-hand panel (lanes 1 to 14). A total of $1 \mu \mathrm{g}$ of GST-EBNA-1 was allowed to bind to Qd (lanes 5 to 13) for $15 \mathrm{~min}$. GST-E2F-1 $(0,1,2.5,5,10$, and $25 \mu \mathrm{g})$ was then added to lanes $5,6,7,8,9$, and 10 , respectively, and allowed to bind for 20 min. As controls, $25 \mu \mathrm{g}$ of GST-E2F-1 DNA-binding mutant (lane 11), GST (lane 12), or GST-Z (lane 13) was added and allowed to bind for $20 \mathrm{~min}$. As further controls, $5 \mu \mathrm{g}$ of GST (lane 2), $25 \mu \mathrm{g}$ of a GST-E2F-1 DNA-binding mutant (lane 3), $5 \mu \mathrm{g}$ of GST-E2F-1 (lane 4), and $25 \mu \mathrm{g}$ of GST-Z (lane 14) were incubated with Qd. A probe containing two EBNA-1 binding sites from oriP was used in the right-hand panel (lanes 15 to 18$)$. GST-EBNA-1 $(1 \mu \mathrm{g})$ was allowed to bind to oriP (lanes 15 to 17 ) for $15 \mathrm{~min}$, after which $25 \mu \mathrm{g}$ of GST-E2F-1 (lane 15) or GST-E2F-1 DNA-binding mutant (lane 16) was added and allowed to bind for $20 \mathrm{~min}$. As a control, $25 \mu \mathrm{g}$ of GST-E2F-1 was incubated with oriP (lane 18).

the wild-type construct, pF13, in EBV-negative Jurkat cells (data not shown), and in EBV-positive Raji cells it was completely repressed, as expected. Unlike the wild-type pF13 construct, however, the mutant pQEco construct was not significantly activated by cotransfected CMV-RPB-3 (Table 1), confirming that the nucleotides within the DNase I footprint are indeed important for E2F responsiveness of $F p$.

E1A activates Fp in transient transfections. E2F is inactive, existing as part of a heteromeric complex that includes $\mathrm{Rb}$, until it is dissociated from the complex (41). The adenovirus protein E1A can disrupt the interaction between $\mathrm{E} 2 \mathrm{~F}$ and $\mathrm{Rb}$, thereby allowing E2F to activate responsive promoters. To show that endogenous levels of E2F were sufficient to upregulate $\mathrm{Fp}$, an expression construct of E1A was cotransfected with pF13 and pCMV-EBNA-1 into Jurkat cells. Overexpression of E1A repeatedly resulted in 3.9-fold ( \pm 1.0 -fold)-greater acetylation than $\mathrm{pF} 13$ plus EBNA-1 alone (Table 1). Activation by E1A was specific because a mutant construct of E1A, which is incapable of disrupting the $\mathrm{Rb}-\mathrm{E} 2 \mathrm{~F}$ complex, repeatedly showed only 1.3 -fold ( \pm 0.6 -fold) activation.

\section{DISCUSSION}

The EBNA proteins are transcription factors essential for latent infection and cell immortalization. The recently discovered $\mathrm{F}$ promoter, one of three now known to govern transcription of the EBNA proteins, is unique in possessing EBNA-1 binding sites. Promoter activity arising from the BamHI-F
TABLE 1. Effects of mutation of the E2F binding site on activation of $\mathrm{Fp}$ and activation of repressed $\mathrm{Fp}$ by endogenous E2F

\begin{tabular}{llcc}
\hline \multirow{2}{*}{$\begin{array}{l}\text { Promoter } \\
\text { construct }\end{array}$} & \multicolumn{3}{c}{$\begin{array}{c}\text { Activation (fold) of following cotransfected } \\
\text { expression construct }{ }^{a} \text { : }\end{array}$} \\
\cline { 2 - 4 } & pCMV-RBP3 & pRSV E1a wt & pRSV E1a $a_{928}$ \\
\hline pQEco & $2.25 \pm 0.43$ & ND & ND \\
pF13 & $30.3 \pm 14.52$ & $3.9 \pm 1.0$ & $1.3 \pm 0.6$ \\
\hline
\end{tabular}

${ }^{a}$ In the first column, $5 \mu \mathrm{g}$ of each promoter construct, $\mathrm{pF} 13$, containing wild-type (wt) sequences, and pQEco, containing three point mutations in the DNase I-footprinted region of Fp, was cotransfected in Raji cells with $5 \mu \mathrm{g}$ of pCMV-RBP3 (wild-type E2F-1). Results are presented as fold activation above that resulting from cotransfection with pHD101-3 (negative control vector). In the next two columns, Jurkat cells were transfected with $3 \mu \mathrm{g}$ of pF13, $0.5 \mu \mathrm{g}$ of pCMV-EBNA-1 and $6 \mu \mathrm{g}$ of pRSV E1a (wild-type E1A) or pRSV E1a ${ }_{928}$ (E1A $\mathrm{Rb}$ binding mutant). Results are presented as fold activation above that resulting from cotransfection with PCMV-EBNA-1 and pHD101-3, the negative control vector.

region of EBV is negatively autoregulated when the EBNA-1 protein interacts with its low-affinity binding sites in the $Q$ locus $(51,62)$. This result raises the questions of when and how Fp is activated in EBV-infected cells, all of which express EBNA-1, a protein essential for the persistence of latent EBV infection. Recently it has become increasingly clear that EBV gene expression is often regulated by a composite of interactive viral and cellular factors $(19,30,33,36,48,55,56,61,66)$. In this work, we demonstrate that a member of the E2F family of transcription factors can overcome the EBNA-1-mediated repression by interacting directly with DNA within the $Q$ locus. Furthermore, a GST-E2F-1 fusion protein can displace GSTEBNA-1 bound to the $Q$ locus in mobility shift assays.

Autoregulation of Fp during type 1 latency would permit the virus to maintain a minimum threshold level of EBNA-1. Low levels of EBNA-1 would presumably be sufficient to activate the oriP, to which it binds more abundantly, cooperatively, and with a higher affinity (1), before binding to the lower-affinity $Q$ sites and shutting down expression of EBNA-1 from Fp. With the development of type III latency, in which all EBNAs are expressed, Fp would remain inactive and promoter usage for the EBNAs would switch to $\mathrm{Cp}$ or Wp $(31,49)$. EBNA-1 autoregulation could therefore account for the inactivity of Fp in type III latency.

Adding to this model is our finding that a member of the E2F transcription factor family interacts with the $Q$ locus and can overcome the EBNA-1-mediated repression of Fp in infected cells. The E2F transcription factor, first identified by its abilities to bind to and to activate the adenovirus E2 promoter (32), is important in the regulation of cellular genes required for DNA synthesis and replication, such as DHFR, TK and DNA polymerase $\alpha(5,14,24,43)$, as well as genes involved in cell growth, such as c-myc, Cdc2, and cyclin A (12, $26,39,41,63)$. During the $G_{1}$ phase of the cell cycle, E2F-like factors are inactive, existing as a part of heteromeric protein complexes that include the retinoblastoma (RB) protein $(3,4$, $6,9,15,21,25)$. Upon entry into $S$ phase, E2F dissociates from the RB protein and is free to activate its target promoters $(2$, $8,37)$.

Because the EBV episome is maintained during latency at a constant copy number and is replicated coordinately early in $S$ phase in the cell cycle, and since EBNA-1 is the only viral protein required for episomal replication, it is likely that expression or function of EBNA-1 is under cell cycle control. As more activated E2F becomes available in the cell at the $\mathrm{G}_{1} / \mathrm{S}$ boundary, it could activate $\mathrm{Fp}$ by displacing EBNA-1 from the $Q$ locus. This mechanism must be unique in EBV to 
the $\mathrm{Q}$ locus, since in our assays E2F-1 clearly does not interact with the higher-affinity EBNA-1 binding sites within oriP. The newly expressed EBNA-1 could then activate latent episomal replication and coordinately populate the progeny cells with episomes. This type of regulation, which would allow the virus to maintain the episome without expressing all of its latent genes, is consistent with current models for type 1 latency $(31,49)$.

It has also been suggested that $\mathrm{Fp}$ is activated following induction to the cytolytic phase of EBV infection (34). While our current results do not directly address this issue, it has been known for years that induction of lytic viral replication follows entry into $S$ phase (20). If Fp is indeed active during the lytic phase of EBV infection, its activity may be triggered, at least in part, by the higher levels of active E2F available in the cell at the start of $S$ phase $(28,54)$. Clearly, the potential cell cycle control of this promoter deserves further investigation. The E2F activity we have characterized is of considerable interest because of the potentially two new binding sites we have identified. Possibly, both sites work cooperatively to activate Fp. E2F exists as a family of transcription factors $(8,17,27)$, but only narrow variations on a single consensus binding site have been tolerated in binding assays (41). Thus, it has not been possible to identify other promoters that E2F may activate. Although the exact contact points of the E2F factor binding in the $\mathrm{Q}$ locus have not yet been precisely identified, the 15-bp sequence we have mapped by DNase footprinting (5'-GGATGGCGGGTAATA-3') should prove useful in a number of cell biologic contexts. Our results suggest that an E2F-1-like protein is involved in the regulation of $\mathrm{Fp}$. In mobility shift assays, the complex bound to Qe is inhibited by some E2F binding sites but not others, whereas a complex formed with the previously described E2F site from the E2 promoter (E2F) is inhibited by all sites. On the basis of mobility shift assays, it appears that the repression of $\mathrm{Fp}$ is overcome by displacement of EBNA-1 by E2F. In additional work, an E2F mutant, impaired in its transactivation domain (28), could only partially overcome EBNA-1 repression in transient-transfection assays (data not shown). This result suggests that the transactivation domain may contribute to overcoming Fp repression.

The discovery $(51,52,58)$ and characterization of this new promoter illustrate the complexity of EBV gene expression and demonstrate a new regulatory mechanism that invokes downstream activator and repressor elements not previously reported in EBV genes. The coordinate regulation of Fp by both EBNA-1 and E2F suggests a new way in which the virus may subvert use of cell cycle regulatory factors to bring about ordered replication of episomes. It now becomes of considerable interest to determine whether EBNA-1 action in oriP uses a parallel mechanism that also invokes cellular proteins such as the OBP-1 protein, recently described by Wen et al. (64), or others not yet identified.

\section{ACKNOWLEDGMENTS}

We thank Jane Azizkhan, Michael Wade, Steven Bachenheimer, Tim Kowalik, and Shannon Kenney for many helpful discussions, for sharing reagents, and for critically reviewing the manuscript. We are also grateful to Kristian Helin of the Ed Harlow laboratory for his generous gift of the GST-RPB-3 fusion protein as well as the CMV-RBP-3 expression plasmid. pRSV E1a Neo and pRSV E1a $a_{928}$ Neo were generous gifts from David Johnson of Joseph Nevins' laboratory. Douglas Cress of Joseph Nevins' laboratory kindly provided the wild-type GST-E2F-1 and GST-E2F-1 DNA-binding mutant. We also thank Nick Dyson and Ed Harlow for providing the KH95 monoclonal antibody and Jaap Middeldorp for providing the EBNA. OTx1 monoclonal antibody.
This work was supported by grant P01CA19014 from the National Cancer Institute. N.S.S. is supported by training grant 5T32 CA09156 from the National Cancer Institute, DHHS.

\section{REFERENCES}

1. Ambinder, R. F., W. A. Shah, D. R. Rawlins, G. S. Hayward, and S. D. Hayward. 1990. Definition of the sequence requirements for binding of the EBNA-1 protein to its palindromic target sites in Epstein-Barr virus DNA. J. Virol. 64:2369-2379.

2. Bagchi, S., P. Raychaudhuri, and J. R. Nevins. 1990. Adenovirus E1A protein can dissociate heteromeric complexes involving the E2F transcription factor: a novel mechanism for E1A transactivation. Cell 62:659-669.

3. Bagchi, S., R. Weinmann, and P. Raychaudhuri. 1991. The retinoblastoma protein copurifies with E2F-1, and E1A-regulated inhibitor of the transcription factor E2F. Cell 65:1063-1072.

4. Bandara, L. R., J. P. Adamczewski, T. Hunt, and N. B. LaThangue. 1991. Cyclin A and the retinoblastoma gene product complex with a common transcription factor. Nature (London) 352:249-251.

5. Blake, M., and J. Azizkhan. 1989. Transcription factor E2F is required for efficient expression of the hamster dihydrofolate reductase gene in vitro and in vivo. Mol. Cell. Biol. 9:4994-5002.

6. Chellappan, S. P., S. Hiebert, M. Mudryj, J. Horowitz, and J. R. Nevins. 1991. The E2F transcription factor is a cellular target for the RB protein. Cell 65:1053-1061.

7. Chen, M.-R., J. M. Middeldorp, and S. D. Hayward. 1993. Separation of the complex DNA binding domain of EBNA-1 into DNA recognition and dimerization subdomains of novel structure. J. Virol. 67:4875-4885.

8. Chittenden, T., D. M. Livingston, and J. A. DeCaprio. 1993. Cell cycle analysis of E2F in primary human T cells reveals novel E2F complexes and biochemically distinct forms of free E2F. Mol. Cell. Biol. 13:3975-3983.

9. Chittenden, T., D. M. Livingston, and W. G. Kaelin, Jr. 1991. The T/E1A-binding domain of the retinoblastoma product can interact selectively with a sequence-specific DNA-binding protein. Cell 65:1073-1082.

10. Cleary, M. L., R. F. Dorfman, and J. Sklar. 1986. Failure in immunological control of the virus infection: post-transplant lymphomas, p. 163-181. In M. A. Epstein, and B. G. Achong (ed.), The Epstein-Barr virus: recent advances. Heinemann, London.

11. Cress, W. D., D. G. Johnson, and J. R. Nevins. 1993. A genetic analysis of the E2F-1 gene distinguishes regulation by Rb, p107, and adenovirus E4. Mol. Cell. Biol. 13:6314-6325.

12. Dalton, S. 1992. Cell cycle regulation of the human cdc2 gene. EMBO J. 11:1797-1804.

13. Davis, M., S. Kenney, J. Kamine, J. Pagano, and E. S. Huang. 1987. Immediate-early gene region of human cytomegalovirus transactivates the promoter of human immunodeficiency virus. Proc. Natl. Acad. Sci. USA 84:8642-8646.

14. Dou, Q.-P., J. L. Fridovich-Keil, and A. B. Pardee. 1991. Inducible proteins binding to the murine thymidine kinase promoter in late G1/S phase. Proc. Natl. Acad. Sci. USA 88:1157-1161.

15. Flemington, E. K., S. H. Speck, and W. G. Kaelin, Jr. 1993. E2F-1-mediated transactivation is inhibited by complex formation with the retinoblastoma susceptibility gene product. Proc. Natl. Acad. Sci. USA 90:6914-6918.

16. Furnari, F. B., M. D. Adams, and J. S. Pagano. 1992. Regulation of the Epstein-Barr virus DNA polymerase gene. J. Virol. 66: 2837-2845.

17. Girling, R., J. Partridge, L. Bandara, N. Burden, N. Totty, J. J. Hsuan, and N. B. La Thangue. 1993. A new component of the transcription factor DRTF1/E2F. Nature (London) 362:83-87.

18. Gorman, C. M., L. F. Moffat, and B. H. Howard. 1982. Recombinant genomes which express chloramphenicol acetyl-transferase in mammalian cells. Mol. Cell. Biol. 2:1044-1051.

19. Gutsch, D. E., E. A. Holley-Guthrie, Q. Zhang, B. Stein, M. A. Blanar, A. S. Baldwin, and S. C. Kenney. 1994. The bZIP transactivator of Epstein-Barr virus, BZLF1, functionally and physically interacts with the p65 subunit of NF-кB. Mol. Cell. Biol. 4:1939-1948.

20. Hampar, B., A. Tanaka, M. Nonoyama, and J. G. Derge. 1974. Replication of the resident repressed Epstein-Barr virus genome 
during the early S-phase (S-1 period) of nonproducer Raji cells. Proc. Natl. Acad. Sci. USA 71:631-635.

21. Helin, K., E. Harlow, and A. Fattaey. 1993. Inhibition of E2F-1 transactivation by direct binding of the retinoblastoma protein. Mol. Cell. Biol. 13:6501-6508.

22. Helin, K., J. A. Lees, M. Vidal, N. Dyson, E. Harlow, and A. Fattaey. 1992. A cDNA encoding a pRB-binding protein with properties of the transcription factor E2F. Cell 70:337-350.

23. Helin, K., C. L. Wu, A. R. Fattaey, J. A. Lees, B. D. Dynlacht, C. Ngwu, and E. Harlow. 1993. Heterodimerization of the transcription factors E2F-1 and DP-1 leads to cooperative trans-activation. Genes Dev. 7:1850-1861.

24. Hiebert, S. W., M. Blake, J. Azizkhan, and J. R. Nevins. 1991. Role of E2F transcription factor in E1A-mediated transactivation of cellular genes. J. Virol. 65:3547-3552.

25. Hiebert, S. W., S. P. Chellappan, J. M. Horowitz, and J. R. Nevins. 1992. The interaction of $\mathrm{pRB}$ with E2F inhibits a the transcriptional activity of E2F. Genes Dev. 6:177-185.

26. Hiebert, S. W., M. Lipp, and J. R. Nevins. 1989. E1A dependent trans-activation of the human MYC promoter is mediated by the E2F factor. Proc. Natl. Acad. Sci. USA 86:3594-3598.

27. Huber, H. E., G. Edwards, P. J. Goodheart, D. R. Patrick, P. S. Huang, M. Ivey-Hoyle, S. F. Barnette, A. Olifi, and D. C. Heimbrook. 1993. Transcription factor E2F binds DNA as a heterodimer. Proc. Natl. Acad. Sci. USA 90:3525-3529.

27. Huber, H. E., G. Edwards, P. J. Goodheart, D. R. Patrick, P. S. Huang, M. Ivey-Hoyle, S. F. Barnette, A. Olifi, and D. C. Heimbrook. 1993. Transcription factor E2F binds DNA as a heterodimer. Proc. Natl. Acad. Sci. USA 90:3525-3529.

27a.Johnson, D., and J. Nevins. Unpublished results.

28. Johnson, D. G., J. K. Schwarz, W. D. Cress, and J. R. Nevins. 1993. Expression of transcription factor E2F1 induces quiescent cells to enter S-phase. Nature (London) 365:349-352.

29. Jones, C. H., S. D. Hayward, and D. R. Rawlins. 1989. Interaction of the lymphocyte-derived Epstein-Barr virus nuclear antigen EBNA-1 with its DNA binding sites. J. Virol. 63:101-110.

30. Kenney, S., E. Holley-Guthrie, E. B. Quinlivan, D. Gutsch, Q. Zhang, T. Bender, J. F. Giot, and A. Sergeant. 1992. The cellular oncogene c-myb can interact synergistically with the Epstein-Barr virus BZLF-1 transactivator in lymphoid cells. Mol. Cell. Biol. 12:136-146.

31. Kerr, B. M., A. L. Lear, M. Rowe, D. Croom-Carter, L. S. Young, S. M. Rookes, P. H. Gallimore, and A. B. Rickinson. 1992. Three transcriptionally distinct forms of Epstein-Barr virus latency in somatic cells hybrids: cell phenotype dependence of promoter usage. Virology 187:189-201.

32. Kovesdi, I., R. Reichel, and J. R. Nevins. 1986. Role of an adenovirus E2 promoter binding factor in E1A mediated coordinate gene control. Proc. Natl. Acad. Sci. USA 84:2180-2184.

33. Kupfer, S., and W. Summers. 1990. Identification of a glucocorticoid-responsive element in Epstein-Barr virus. J. Virol. 64:1984-1990.

34. Lear, A. L., M. Rowe, M. G. Kurilla, S. Lee, S. Hebderson, E. Kieff, and A. B. Rickinson. 1992. The Epstein-Barr virus nuclear antigen 1 BamHI-F promoter is activated on entry of EBV-transformed $B$ cells into the lytic cycle. J. Virol. 66:7461-7468.

35. Li, Q. X., L. S. Young, G. Neidobitek, C. W. Dawson, M. Birkenbach, F. Wang, and A. B. Rickinson. 1992. Epstein-Barr infection and replication in a human epithelial cell system. Nature (London) 356:347-350.

36. Lieberman, P., and A. Berk. 1991. The Zta transactivator protein stabilizes TFIID association with promoter DNA by direct protein-protein interaction. Genes Dev. 5:2441-2454.

37. Means, A. L., J. E. Slansky, S. L. McMahon, M. W. Knuth, and P. J. Farnham. 1992. The HIP1 binding site is required for growth regulation of the dihydrofolate reductase gene promoter. Mol. Cell. Biol. 12:1054-1063.

38. Milman, G., and E. S. Hwang. 1987. Epstein-Barr virus nuclear antigen forms a complex that binds with high concentration dependence to a single DNA binding site. J. Virol. 61:465-471.

39. Mudryj, M., S. Devoto, S. Hiebert, T. Hunter, J. Pines, and J. Nevins. 1991. Cell cycle regulation of the E2F transcription factor involves an interaction with cyclin A. Cell 65:1243.

40. Neumann, E., M. Schaefer-Ridder, Y. Wang, and P. H. Hofschnei- der. 1982. Gene transfers into mouse lymphoma cells by electroporation in high electric fields. EMBO J. 1:841-845.

41. Nevins, J. 1992. E2F: a link between the Rb tumor suppressor protein and viral oncoproteins. Science 258:424-429.

42. Nonoyama, M., and J. S. Pagano. 1972. Separation of Epstein-Barr virus DNA from large chromosomal DNA in nonvirus producing cells. Nature (London) New Biol. 238:169.

43. Pearson, B. E., H.-P. Nasheuer, and T. S.-F. Wang. 1991. Human DNA polymerase $\alpha$ gene: sequences controlling expression in cycling and serum-stimulated cells. Mol. Cell. Biol. 11:2081-2095.

44. Pulvertaft, R. J. V. 1965. A study of malignant tumors in Nigeria by short-term tissue culture. J. Clin. Pathol. 18:261-271.

45. Raab-Traub, N. 1992. Epstein-Barr virus and nasopharyngeal carcinoma. Sem. Cancer Biol. 3:297-307.

46. Rawlins, D. R., G. Milman, S. D. Hayward, and G. S. Hayward. 1985. Sequence-specific DNA binding of the Epstein-Barr virus nuclear antigen (EBNA-1) to clustered sites in the plasmid maintenance region. Cell 42:859-868.

47. Reisman, D., and B. Sugden. 1986. Transactivation of an EpsteinBarr viral transcriptional enhancer by the Epstein-Barr viral nuclear antigen 1. Mol. Cell. Biol. 6:3838-3846.

48. Rooney, C., M. Brimmell, M. Buschle, G. Allan, P. J. Farrell, and J. Kolman. 1992. Host cell and EBNA-2 regulation of EpsteinBarr virus latent-cycle promoter activity in B lymphocytes. J. Virol. 66:496-504.

49. Rowe, M., A. L. Lear, D. Croom-Carter, A. H. Davies, and A. B. Rickinson. 1992. Three pathways of Epstein-Barr virus gene activation from EBNA-1 positive latency in B lymphocytes. J. Virol. 66:122-131.

50. Sample, J., L. Brooks, C. Sample, L. Young, M. Rowe, C. Gregory, A. Rickinson, and E. Kieff. 1991. Restricted Epstein-Barr virus protein expression in Burkitt lymphoma is due to a different Epstein-Barr nuclear antigen 1 transcriptional initiation site. Proc. Natl. Acad. Sci. USA 88:6343-6347.

51. Sample, J., E. B. Henson, and C. Sample. 1992. The Epstein-Barr virus nuclear protein 1 promoter active in type 1 latency is autoregulated. J. Virol. 66:4654-4661.

52. Schaefer, B. C., M. Woisetschlager, J. Strominger, and S. H. Speck. 1991. Exclusive expression of Epstein-Barr virus nuclear antigen 1 in Burkitt lymphoma arises from a third promoter, distinct from the promoters used in latently infected lymphocytes. Proc. Natl. Acad. Sci. USA 88:6550-6554.

53. Scheinman, R., A. Beg, and A. Baldwin. 1993. NF-kB p100 (Lyt-10) is a component of H2TF1 and functions as an IкB-like molecule. Mol. Cell. Biol. 13:6089-6101.

54. Shirodkar, S., M. Ewen, J. A. DeCaprio, J. Morgan, D. M. Livingston, and T. Chittenden. 1992. The transcription factor EZF interacts with the retinoblastoma product and a p107-cyclin A complex in a cell cycle-regulated manner. Cell 68:157-166.

55. Sinclair, A. J., M. Brimmell, and P. J. Farrell. 1992. Reciprocal antagonism of steroid hormones and BZLF-1 in switch between Epstein-Barr virus latent and productive cycle gene expression. J. Virol. 66:70-77.

56. Sista, N. D., J. S. Pagano, W. Liao, and S. Kenney. 1993. Retinoic acid is a negative regulator of the Epstein-Barr virus protein (BZLF-1) that mediates disruption of latent infection. Proc. Natl. Acad. Sci. USA 90:3894-3898.

57. Smith, D. B., and K. S. Johnson. 1988. Single-step purification of polypeptides expressed in Escherichia coli as fusions with glutathione-S-transferase. Gene 67:31-40.

58. Smith, P. R., and B. E. Griffin. 1992. Transcription of the EpsteinBarr virus gene EBNA-1 from different promoters in nasopharyngeal carcinoma and B-lymphoblastoid cells. J. Virol. 66:706-714.

59. Su, I. J., and H. C. Hsieh. 1992. Clinicopathological spectrum of Epstein-Barr virus associated T-cell malignancies. Leuk. Lymphoma 7:47-53.

60. Sugden, B., and N. Warren. 1989. A promoter of Epstein-Barr virus which can function during latent infection can be transactivated by EBNA-1, a viral protein required for DNA replication during latent infection. J. Virol. 63:2644-2649.

61. Sung, N., S. Kenney, D. Gutsch, and J. S. Pagano. 1991. EBNA-2 transactivates a lymphoid specific enhancer in the BamHI-C promoter of Epstein-Barr virus. J. Virol. 65:2164-2169. 
62. Sung, N. S., J. Wilson, and J. S. Pagano. 1993. Characterization of cis-acting regulatory elements of the BamHI-F promoter of EBV, p. 239-242. In T. Tursz, J. S. Pagano, D. V. Ablashi, G. de The, G. Lenoir, and G. R. Pearson (ed.), The Epstein-Barr virus and associated diseases. INSERM/John Libbey Eurotext Limited, Lon-don.

63. Thalmeier, K., H. Synovzik, R. Mertz, E. Winnacker, and M. Lipp. 1989. Nuclear factor E2F mediates basic transcription and transactivation by E1A of the human myc promoter. Genes Dev. $3: 327-336$
64. Wen, L. T., A. Tanaka, and M. Nonoyama. 1989. Induction of anti-EBNA-1 protein by 12-O-tetradecanoylphorbol-13-acetate treatment of human lymphoblastoid cells. J. Virol. 63:33153322.

65. Yates, J., N. Warren, and B. Sugden. 1985. Stable replication of plasmids derived from Epstein-Barr virus in various mammalian cells. Nature (London) 313:812-815.

66. Zhang, Q., D. Gutsch, and S. Kenney. 1994. Functional and physical interaction between p53 and BZLF1: implications for Epstein-Barr virus latency. Mol. Cell Biol. 14:1929-1938. 